\title{
Apresentação
}

\section{Três Décadas de Enap e de Escolas de Governo}

Este número da Revista do Serviço Público (RSP) é uma edição especial do periódico realizada em parceria com a Sociedade Brasileira de Administração Pública (SBAP) ${ }^{1}$, cuja chamada pública, lançada em 2016, referia-se então aos "30 anos de Enap, 30 anos de escolas de governo e 30 anos de formação continuada em administração pública" no Brasil, em comemoração às três décadas de criação da Escola Nacional de Administração Pública (Enap).

A ideia de se organizar uma publicação da RSP em coedição com a SBAP surgiu em 2015, durante o II Encontro Brasileiro de Administração Pública (Ebap) realizado no Centro de Ciências Sociais Aplicadas da Universidade Federal do Rio Grande do Norte (CSCA-UFRN). No evento, intitulado "Interlocuções entre a Academia e o Governo no Brasil: entre o saber e o fazer", a SBAP e a Enap iniciaram uma cooperação interinstitucional para buscar uma maior integração entre os programas de pós-graduação stricto sensu em Administração/Gestão Pública do país e a Rede Nacional de Escolas de Governo.

Enunciando os 30 anos da Enap, instituída pelo Decreto no 93.277 de 1986, o edital desta edição especial foi divulgado no primeiro semestre de 2016 , com o mote de se refletir sobre o papel das escolas de governo no treinamento e na formação dos funcionários públicos no Brasil - nos três Poderes e nos três níveis de governo - e no exterior. E especificamente sobre a União, o objetivo era, igualmente, de sugerir um balanço da Política Nacional de Desenvolvimento de Pessoal (Decreto no 5.707 de 2006), decorridos 10 anos de seu estabelecimento, em termos de avaliação da implementação de suas diretrizes e da identificação de experiências inovadoras de capacitação da burocracia federal.

Uma vez encerrada a chamada pública, os 39 artigos recebidos foram avaliados por nós - os editores convidados -, em conjunto com a equipe editorial da RSP, em um estágio denominado de desk review. Ocorrido no segundo semestre de 2016, esse ciclo avaliativo efetuou uma triagem dos manuscritos baseada tanto na verificação de aderência ao tema quanto em uma análise de potencial científico. Foram aprovados 14 artigos para a segunda fase (peer review), na qual os trabalhos

\footnotetext{
${ }^{1}$ Fundada em 2013, a Sociedade Brasileira de Administração Pública (SBAP) funciona como um espaço institucional de articulação dos cursos de mestrado e doutorado dessa área do conhecimento com as organizações públicas e seu corpo profissional, visando à promoção da Administração/Gestão Pública como disciplina no país. Para mais informações sobre a SBAP, acesse o website: $\underline{\text { https://sbap.org.br/. }}$
} 
foram examinados pelo sistema de double blind review. Alguns contratempos operacionais, como a dificuldade de se encontrar especialistas no tema para a emissão dos pareceres, atrasaram o processo de avaliação, postergando o lançamento desta edição especial que ora apresentamos. Contudo, nesse ínterim, a RSP/Enap e a SBAP não arredaram do objetivo de realizar esta edição.

Em razão desse longo processo editorial - desde a apreciação dos artigos até a editoração deste número -, desculpamo-nos pela delonga com os autores e, publicamente, agradecemos a confiança da equipe editorial da RSP e a persistência do staff administrativo da Enap, além da vital assistência dos avaliadores ad hoc. Ao fim e ao cabo, esta edição especial é um marco nas relações entre a SBAP e a Enap (juntamente com os 11 livros da "Coleção Gestão Pública", recémpublicados ${ }^{2}$ ) e apresenta-se como uma contribuição técnico-científica para os acadêmicos e gestores públicos orientados para o desenvolvimento de pessoas no Estado brasileiro.

Com 82 anos de história, completados em 2019, a RSP é um patrimônio da comunidade acadêmica de Administração Pública e dos quadros técnicos do funcionalismo público brasileiro, uma vez que o seu acervo é per se um memorial da gestão pública nacional no século 20. Como o periódico mais longevo sobre gestão governamental e políticas públicas no país, a revista manteve, neste limiar do século 21 , a tradição de publicar textos de professores-pesquisadores e de practitioners, justapondo teoria e prática em prol do aperfeiçoamento do serviço público. Na classificação do Qualis/Capes (2013-2016), a RSP obteve a classificação B1 na área de avaliação de Ciência Política e Relações Internacionais e a classificação B2 na área de avaliação de Administração Pública e de Empresas, Ciências Contábeis e Turismo, configurando-se, assim, como uma das publicações com status de 'produção qualificada' no domínio do Campo de Públicas. ${ }^{3}$

Consciente da importância de publicações como a RSP para a difusão do conhecimento de Administração Pública, a SBAP, em 2016, criou o Fórum de Periódicos de Administração Pública, congregando os editores das principais revistas nacionais desse campo do saber. Essa atividade resultou em parcerias da Diretoria da SBAP com as equipes editoriais dos periódicos, englobando acordos

\footnotetext{
${ }^{2}$ A Enap e a SBAP publicaram, há pouco tempo, uma coleção de livros de Gestão Pública, composta por 11 obras que têm como eixo central o debate sobre temas de administração pública no contexto brasileiro. As versões digitais (ebooks) estão disponíveis no repositório da Enap pelo link: https://repositorio.enap.gov.br/handle/1/4264

E para uma concisa apresentação desses livros, bem como algumas notas da profícua parceria entre Enap e SBAP, sugerimos o texto do Prof. Thiago Ferreira Dias, vice-presidente da SBAP (2016-2018), na revista APGS/UFV: https://periodicos.ufv.br/apgs/article/view/8957

${ }^{3}$ Nas discussões prévias do novo Qualis/Capes (2017-2021) único para todas as áreas de avaliação, a RSP já está pré-indicada no estrato $A 4$ e tem potencial para alcançar a faixa $A 3$.
} 
de fast track de artigos premiados no congresso Ebap e a estruturação de edições especiais como esta - que, aliás, foi a primeira chamada pública de uma revista doméstica coeditada com a nossa associação científica. Ademais, na esteira desse movimento de sinergia, alguns ex-diretores e conselheiros da SBAP tornaram-se membros do Comitê Editorial e do Conselho Científico da RSP.

Enfim, é simbólico que a RSP, editada pela Enap - referência de escola de governo (EG) em território nacional -, publique este número sobre a atuação e os modelos de EGs e as funções inerentes ao subsistema de treinamento e desenvolvimento (T\&D) no setor público. Afinal, a Enap, com seu pioneirismo e liderança, é a instituição que mais tem operacionalizado o conceito de EG e disseminado a noção de capacitação como elemento estratégico na gestão pública brasileira nos últimos decênios. Assim, reconhecendo o protagonismo dessa escola e celebrando a propagação das EGs pelo país desde então, nomeamos esta edição especial de "Três Décadas de Enap e de Escolas de Governo".

$\mathrm{Na}$ sequência, objetivando elucidar nessa imbricação entre o percurso da Enap (1986-2019) e a evolução das Escolas de Governo no Brasil nesse intervalo temporal, compendiamos algumas informações para uma breve contextualização do tema.

\section{Contextualizando o Tema: três décadas de Enap e de escolas de governo no Brasil}

Historicamente, a expressão escola de governo admite diversas definições, abarcando um continuum de órgãos público-estatais, faculdades/universidades (públicas e privadas) e organizações não governamentais voltados para o treinamento, capacitação e formação de funcionários públicos para o serviço civil e políticos.

$\mathrm{Na}$ verdade, trata-se de um anglicismo, uma vez que o vocábulo "School of Government", em inglês, compreende aplicações que podem ir além ou aquém daquilo que temos designado como escolas de administração pública. Government, no sentido anglo-saxão, pode se referir a Estado, mas governo, na tradição latina, diz respeito mais peculiarmente ao exercício da função governativa no âmbito do Poder Executivo. Na nossa praxe, escolas de governo são escolas governamentais de administração pública? São escolas de formação de lideranças político-partidárias? São escolas universitárias devotadas ao Campo de Públicas?

No Brasil, grosso modo, o Departamento Administrativo do Serviço Público (Dasp), criado em 1938, a Escola Brasileira de Administração Pública da Fundação Getulio Vargas (Ebap/FGV), instituída em 1952, e o Instituto Brasileiro de Administração Municipal (Ibam), fundado - tal como a Ebap-FGV - em 1952, são alguns dos 
empreendimentos pioneiros que ilustram a amplitude e heterogeneidade, do ponto de vista institucional, do significado do termo escola de governo. ${ }^{4}$

Já no cenário internacional e na acepção de ente estatal, a escola de governo tipicamente referenciada pela literatura de Administração Pública - no século 20 - foi a École Nationale d'Administration (ENA). O modelo francês, calcado na preparação de quadros de nível superior para a função de direção pública, serviu de inspiração para a constituição de uma EG congênere no Brasil: a Escola Nacional de Administração Pública (Enap), concebida em 1986 como uma diretoria da então Fundação Centro de Formação do Servidor Público (Funcep). Naquela época, no prelúdio da Nova República com o reestabelecimento da democracia, a visão era de proporcionar a formação de uma nova burocracia estável e permanente no Governo Federal, amparada pela implantação de carreiras de Estado.

Em 1990, a Lei no 8.140 alterou a denominação da Funcep para Enap, vinculando-a, na ocasião, à Secretaria da Administração da Presidência da República. Todavia, é a partir de 1995 que a Enap tem um impulso e assume a feição de 'universidade corporativa' do Governo Federal. Subordinada ao Ministério de Administração e Reforma do Estado (Mare), formado no primeiro mandato de FHC, a escola tornouse estratégica para a difusão das ideias gerencialistas do Plano Diretor de Reforma do Aparelho do Estado (PDRAE) e para o T\&D de recursos humanos - sobretudo os do ciclo de gestão pública - para a modernização do Poder Executivo. Destarte, engendrava-se um alinhamento entre a agenda governamental e as diretrizes dos planos dos ministérios com a política de desenvolvimento de pessoal e a oferta de cursos da escola.

Desde aquele momento, a Enap adquiriu uma centralidade no sistema de T\&D no setor público brasileiro, com uma miríade de atividades instrutivas e práticas conexas, quais sejam: formação inicial e aperfeiçoamento de carreiras, educação continuada presencial e à distância, programas de pós-graduação lato sensu e stricto sensu, realização de pesquisas aplicadas e publicações (revistas, livros, relatórios e textos de discussão), projetos de gestão do conhecimento e organizações de prêmios de inovação, seminários temáticos e workshops técnico-gerenciais.

Com o fito de ampliar a eficácia das organizações público-estatais que atuam com T\&D dos funcionários públicos das três esferas da federação, a Enap tem também fomentado e gerido - no decorrer dos últimos 10 anos - a Rede Nacional de Escolas de Governo, composta por 262 instituições de diferentes trajetórias e

\footnotetext{
${ }^{4}$ Um exemplo adicional de uma escola de governo vanguardista no país, pertencente ao aparelho do Estado e com significativos afazeres até os dias correntes, é o Instituto Rio Branco, estabelecido em 1945 como um núcleo de estudos sobre diplomacia e relações internacionais para a instrução dos servidores do Ministério das Relações Exteriores.
} 
formatos, como EGs propriamente ditas, centros de treinamento e formação de órgãos públicos, universidades corporativas de empresas públicas, dentre outras. Em termos numéricos, são 96 'escolas' pertencentes à União, 104 estaduais e 62 de nível municipal. Acima de $70 \%$ vinculam-se ao Poder Executivo, e as demais estão distribuídas entre os Poderes Legislativo e Judiciário, além do Ministério Público. ${ }^{5}$

Nesse agrupamento de EGs, algumas poucas foram constituídas entre os anos 1950 e 1980, conquanto a grande maioria foi fundada nas últimas três décadas, tendo como ímpeto a Emenda Constitucional (EC) no 19/1998 que, dentre várias disposições para a reforma administrativa do Estado brasileiro, prevê que "(...) $a$ União, os Estados e o Distrito Federal manterão escolas de governo para a formação e o aperfeiçoamento dos servidores públicos (...)" - trecho do Art. 5o, § 2ㅇ, da EC 19/1998, que alterou o art. 39 da Constituição Federal de 1998.

Com esse estímulo jurídico-legal e à luz de experiências de escolas predecessoras à referida EC - como a Enap -, multiplicou-se a quantidade de EGs no Brasil, sobretudo no nível subnacional. Afora a predominância dessas instituições no Executivo, no Poder Legislativo, por exemplo, a Associação Brasileira de Escolas do Legislativo (Abel) registra 208 escolas, somando as unidades das Câmaras Municipais, Assembleias Legislativas Estaduais, Tribunais de Contas e Congresso Nacional (Câmara dos Deputados e Senado Federal). ${ }^{6}$ E nas 'escolas' das Casas Legislativas, para mais da capacitação de técnicos e parlamentares, coexistem os projetos de educação política para os cidadãos. Vale salientar, do mesmo modo, que o vocábulo 'escolas de governo' tem sido empregado, similarmente, por muitas entidades do terceiro setor que trabalham com o T\&D de pessoal para o serviço público e/ou a formação de lideranças políticas.

Logo, considerando essa expansão e diversificação hodierna das EGs no país, o rol de oportunidades de investigação científica e aplicada de tal objeto de estudo é vasto. E, de alguma maneira, esta edição especial denota um esforço para compilar algumas reflexões sobre o tema. Embora ela não cubra todas as facetas/vertentes tocantes ao assunto, é um primeiro passo para a valorização desse front de pesquisa na nossa comunidade acadêmica de Administração/Gestão Pública - tomando como pano de fundo o itinerário percorrido e a bagagem acumulada sobre T\&D no setor público brasileiro desde a concepção da Enap.

A Enap, diga-se de passagem, haja vista o prestígio alcançado e seu predicado de benchmark para as demais escolas de governo no Brasil, tornou-se um dos pontos

\footnotetext{
${ }^{5}$ Dados referentes ao ano de 2016. Informações adicionais sobre a Rede Nacional de Escolas de Governo estão disponíveis pelo link: https://redeescolas.enap.gov.br.

${ }^{6}$ Para um mapeamento das Escolas do Legislativo e de Contas no Brasil, visite o website da Abel: https://www. portalabel.org.br .
} 
focais na temática. São vários os artigos científicos, dissertações de mestrado e teses de doutorado que investigam a escola ou a utilizam como unidade de análise. A título de ilustração, na biblioteca eletrônica SPELL ${ }^{\circledR}$ (spell.org.br), com 124 periódicos nacionais indexados do campo do saber de Administração (incluindo a Administração Pública), tem 25 manuscritos que, direta ou indiretamente, abordam a Escola Nacional de Administração Pública, com a sigla Enap aparecendo no título, resumo e/ou nas palavras-chave dos textos. E entre os trabalhos de pós-graduação, citamos um dos mais recentes: o doutoramento, em 2017, da professora Manuela Ramos da Silva, docente da Universidade Federal do Sergipe (UFS), na Escola de Administração da Universidade Federal da Bahia (EA-UFBA) "História Organizacional da Enap: uma análise dos papéis desempenhados e das competências organizacionais desenvolvidas".7

E, doravante, a julgar pelo Decreto no 9.991/2019, que reorienta a Política Nacional de Desenvolvimento de Pessoas da Administração Pública Federal, atribuindo à Enap - após a fusão com a Escola de Administração Fazendária (Esaf) - a coordenação do Sistema de Escolas de Governo da União, ratifica-se a sua posição nuclear para o T\&D de servidores públicos construída durante os seus 33 anos de existência.

\section{Prefácio desta Edição Especial: apresentação dos sete artigos}

Após a avaliação dos 14 manuscritos aprovados, preliminarmente, na etapa de desk review, a fase de peer review recomendou seis artigos para publicação nesta edição especial, complementada com um trabalho convidado. $O$ elenco de textos expressa variados tópicos atinentes às Escolas de Governo, a saber: estudos comparados entre EGs de diversos países; modelagem de redes colaborativas de ações de capacitação entre organizações públicas; pesquisa comparativa entre EGs do sistema de escolas de governo da União; investigação do papel das EGs como elemento estruturante do ideário da New Public Management; análise da percepção dos servidores públicos sobre os efeitos do processo formativo; averiguação da convergência de propósitos entre processo seletivo, curso de formação e atribuições legais em carreiras do ciclo de gestão; e construção da memória das Escolas do Legislativo no Brasil.

Da perspectiva metodológica, os textos abrangem desde trabalhos descritivos até artigos analítico-propositivos, predominantemente de abordagem qualitativa, cujos loci empíricos envolvem EGs estrangeiras e brasileiras - e, neste caso, nacionais

\footnotetext{
${ }^{7}$ Essa tese de doutorado, em formato digital, está disponível no repositório institucional da UFS pelo link: https://ri.ufs.br/handle/riufs/2072.
} 
e subnacionais - e universidades públicas. Os sete trabalhos reúnem 23 autores que pertencem a nove organizações entre escolas de governo, fundações de apoio científico, institutos de pesquisa e instituições de educação superior, sobressaindo, quantitativamente, a filiação institucional à própria Enap e à Universidade de Brasília (UnB).

O primeiro artigo, "Schools of Government: a comparative study", escrito por Pedro Paulo Hollanda, Claudia Rosa, Ciro Fernandes e Samantha Amorim, descreve o funcionamento de oito EGs de distintos países, comparando-as a partir de categorias como: localização dentro do governo, objetivos organizacionais, aspectos de financiamento, quadro de pessoal, estrutura administrativa e principais atividades de T\&D. O panorama internacional traçado pelos autores, utilizando-se de uma amostra intencional com unidades de análise dos cincos continentes, é um subsídio para a compreensão da diversidade do aparato institucional das escolas de governo em torno do mundo.

O artigo seguinte, "Escolas de Governo e Redes de Capacitação no Setor Público: perspectivas metodológicas para governança", elaborado por Diogo Fonseca, Pedro Paulo Meneses, Igor Loyola Souza e Pedro Paulo Hollanda, apoiando-se no instrumental da análise de redes sociais e aplicando-o para o compartilhamento de conhecimentos/recursos entre as organizações, propõe um modelo analítico de padrões de relacionamento interinstitucionais para as ações de capacitação. Trata-se de uma contribuição teórico-metodológica que pode ser empregada pelas Escolas de Governo para o aprimoramento das redes de desenvolvimento de pessoal na ambiência da Administração Pública.

Na sequência, o terceiro artigo, "Schools of Government's roles and challenges for institutionalization: a comparative study in the Brazilian Federal Public Sector", de autoria de Diogo Fonseca, Marizaura Camões, Pedro Luiz Cavalcante, Joselene Lemos e Pedro Palotti, analisando 17 escolas de governo da União (14 do Poder Executivo e três do Poder Legislativo), propõe uma tipologia assentada no escopo das atividades educacionais e no público-alvo. Pelo prisma da governança em rede para o aperfeiçoamento da profissionalização no serviço público - discutido no segundo artigo, supracitado -, esse trabalho identifica aspectos comuns entre as EGs federais, trazendo algumas pistas para o delineamento de arranjos cooperativos entre elas.

O quarto artigo, "Escolas de governo e seu papel estruturante na formação de servidores em tempos de Nova Gestão Pública: relatos de experiências no Nordeste brasileiro", redigido por Jorge Luiz Evaristo, Ana Cristina Batista-dosSantos, Rafaela Aguiar, Juliana Sousa e Andreza Franco, explora o nexo entre o construto 'escolas de governo' e os princípios da Nova Gestão Pública (NGP), a partir 
do estudo de caso de uma EG subnacional. $\mathrm{O}$ trabalho evidencia o alinhamento entre a missão/finalidade da EG tratada - não especificada e localizada na região Nordeste - com os desafios de incorporação de um modelo de gestão pública.

Posteriormente, o quinto artigo, "Pós-Graduação de Servidores Públicos: percepções de egressos sobre os efeitos de uma especialização", de Simone Gama Barros, discute as implicações do Curso de Pós-Graduação Lato Sensu em Gestão Pública Municipal, ofertado na modalidade de educação à distância pela Universidade Aberta do Brasil (UAB) e financiado pela Capes, na vida pessoal, profissional e acadêmica dos ex-alunos. Trabalho de abordagem quantitativa, a coleta de dados utilizou-se de uma survey respondida por 1352 egressos - cerca de 20\% dos formados nessa especialização no quinquênio 2011-2015. Os resultados indicam efeitos positivos para os indivíduos e para o ramo laboral e o ambiente social em que eles estão inseridos.

Completando a lista de trabalhos oriundos do fluxo de avaliação, o sexto artigo, "O Especialista em Políticas Públicas e Gestão Governamental: um ensaio sobre a convergência de propósitos entre o processo seletivo e as atribuições legais", assinado por Rosane Maria Pio Silva e Andréa Gonçalves, é um excerto de uma tese de doutorado - elaborada pela primeira autora (e orientada pela segunda autora) - defendida no Programa de Pós-Graduação em Administração (PPGA) da UnB, em 2016. O manuscrito debate as (in)compatibilidades entre o sistema de ingresso da carreira de EPGG no Governo Federal, incluindo os conteúdos das provas aplicadas e do curso de formação ministrado pela Enap, vis-à-vis as incumbências desse profissional na máquina administrativa.

E por último, mas não menos importante, o sétimo artigo, convidado para esta edição especial e intitulado "Gênese das Escolas do Legislativo no Brasil: apontamentos históricos sobre a criação da EL-ALMG", de William Maximiliano Melo e Fernando Coelho, minucia as origens das escolas de governo no Parlamento, clarificando como essas estruturas de qualificação de recursos humanos e educação política surgiram na década de 1990 . Em linhas gerais, o trabalho mostra que as primeiras escolas do Legislativo, também conhecidas como Escolas do Parlamento, emanaram de processos de modernização administrativa em algumas Casas Legislativas do país perante a dinâmica de redemocratização e os ditames das Constituições federal (1988) e estaduais (1989).

Esperamos que você, leitor ou leitora, aproveite esta edição especial da RSP em parceria com a SBAP. Fazemos votos de que o teor e conteúdo dos artigos produzam insights e debates na seara do T\&D de pessoal no setor público, com vistas à melhoria contínua da gestão e das políticas públicas no Brasil. 


\section{Fernando de Souza Coelho}

Professor do Programa de Pós-Graduação em Gestão de Políticas Públicas da Universidade de São Paulo (USP). Presidente da Sociedade Brasileira de Administração Pública (2016-2018).

\section{Frederico Lustosa da Costa}

Professor do Programa de Pós-Graduação em Administração da Universidade Federal Fluminense (UFF). Presidente da Sociedade Brasileira de Administração Pública (2014-2016).

\section{Thiago Ferreira Dias}

Professor do Programa de Pós-Graduação em Gestão Pública da Universidade Federal do Rio Grande do Norte (UFRN). Vice-Presidente da Sociedade Brasileira de Administração Pública (2016-2018). 